\title{
A Method for Breeding New Cultivars of Machine-harvested Raspberries with High Yield
}

\author{
M. Joseph Stephens ${ }^{1}$, Peter A. Alspach, and Ron A. Beatson \\ The New Zealand Institute for Plant \& Food Research Limited, Motueka Research Centre, 55 Old Mill \\ Road, Motueka 7198, New Zealand \\ Chris Winefield \\ Lincoln University, Faculty of Agriculture and Life Sciences, P.O. Box 84, Lincoln 7647, Canterbury, \\ New Zealand \\ Emily J. Buck \\ The New Zealand Institute for Plant \& Food Research Limited, Batchelar Road, Private Bag 11600 , \\ Palmerston North, 4442 New Zealand
}

\begin{abstract}
Additional Index words. Rubus idaeus, yield components, genetic gain, family selection
Abstract. The Pacific northwestern (PNW) region of the United States is well known for production of machineharvested red raspberries (Rubus idaeus) for process markets. The cultivar Meeker, developed in the 1960s, is well suited to this area and for machine-harvesting, but it is susceptible to raspberry bushy dwarf virus and root rot caused by Phytophthora rubi. Despite the efforts of several breeding programs, 'Meeker' is still the predominant cultivar for commercial production in the PNW. One of the major difficulties with breeding new berry fruit cultivars is the timeconsuming nature of collecting fruit yield and quality data on large seedling populations. For fruit yield, visual scoring assessment methods are commonly used for seedling populations, but these may be poor predictors of yield. Consequently, visual scores for yield can result in less genetic improvement and thus can adversely affect successful cultivar development. Total yield measured by hand-harvesting is labor-intensive and does not assess machineharvestability, but machine-harvesting is not practical to measure on individual plants. In this study we set out to see if we could bulk machine-harvest full-sib family plots for among-family selection and use yield component data on individuals within the plots for within-family selection. Using best linear unbiased predictors, we estimated machineharvest yield breeding values for our individual seedlings and found higher genetic gain per generation using estimated individual machine-harvest breeding values $\mathbf{( 7 . 6 \% )}$ than using hand-harvested breeding values $(6.5 \%)$. Implications for breeding machine-harvest red raspberries are discussed.
\end{abstract}

Commercial red raspberry cultivars suited to machineharvest and process markets need to have a high yield of good-quality fruit that is easily removed during the harvest operations. In the PNW, this has been achieved using the cultivar Meeker, which was developed in the 1960s (Moore and Daubeny, 1993). This cultivar is only two and three generations removed from wild species representing the native North American red raspberry, Rubus idaeus ssp. strigosus, and European red raspberry, $R$. idaeus ssp. vulgatus. Since 'Meeker' was released, a number of breeding programs have developed new red raspberry types for machine-harvest (Kempler et al., 2006, 2007; Moore and Finn, 2007). Nevertheless, 'Meeker' still remains the dominant process red raspberry cultivar grown in the PNW, although 'Wakefield', released in 2009 , accounted for $19 \%$ of new plantings in Washington State in 2011.

One of the major difficulties with breeding new red raspberry cultivars is the time-consuming nature of collecting fruit yield and fruit quality data on individual genotypes from seedling populations. Typically breeders might rely on visual

Received for publication 6 Aug. 2012. Accepted for publication 25 Sept. 2012. We thank Julie Enfield, Micah Blondeau, Lawrence Graham, and Donna Graham who helped to coordinate the harvest; David Stevenson and Dave Andersen for chemistry analyzes; and Adam Enfield and Enfield Farms Inc. for field management.

${ }^{1}$ Corresponding author. E-mail: jo.stephens@plantandfood.co.nz. scores for a number of key traits, including yield, which may not be accurate. The lack of objective measurements on seedling populations may be a contributing factor to the low number of successful new commercial machine-harvest cultivars.

Ways to reduce the cost associated with yield measurements in red raspberry have been investigated in New Zealand by Stephens et al. (2009) and in the PNW by Stephens et al. (2012). In Washington State, Stephens et al. (2012) identified two key components of yield (berry weight and lateral length) that, when measured in the first two fruiting years from planting, were able to predict total yield in later years $(r=0.55)$, thus enabling a breeder to concentrate on the most promising genotypes when harvesting.

In their study, Stephens et al. (2012) used fruit harvested by hand as the measure of total yield. This is time-consuming and not necessarily applicable to breeding programs focused on developing cultivars suited to machine-harvesting. For machine-harvesting, fruit must be firm and coherent, separate from the receptacle easily with little pedicel breakage, and plant laterals must be strong. However, machine-harvesting individual seedlings for yield measurement is not currently practical because the machine has to stop in a clear space after each seedling plant to allow fruit to be cleared from catcher plates and belts before weighing. For large numbers of seedlings that must be harvested many times in one season, this is not feasible. A previous study by Hall et al. (2002) tried 
to attribute red raspberry machine-harvestability to single traits such as lateral length, receptacle morphology, and fruit firmness. However, no single trait was found to be responsible, indicating that many traits contribute to successful machine-harvest.

Various strategies have been proposed and/or adopted to breed high-yielding cultivars for machine-harvested crops. The modified ear-to-row procedure developed for maize breeding involves selection of best families from bulk harvest of all individuals within a family followed by a recombination event between the best families (growing open-pollinated seed from best families) and selection for best individuals within families (Hallauer et al., 2010). Similarly, amongfamily selection before within-family selection is commonly used in sugarcane, which is another machine-harvested crop (Bischoff and Gravois, 2004; Kimbeng and Cox, 2003; Stringer et al., 2011). Falconer and Mackay (1996) state that among-family selection is useful for traits with low heritability and previous studies have shown that red raspberry yield has low heritability (Stephens et al., 2009, 2012) and thus maybe suited to this strategy. Furthermore, Kimbeng and Cox (2003) suggest among-family selection is especially suited to mechanical harvesting after the advent of mobile weighing machines.

The benefits of using mixed models and best linear unbiased predictors (BLUP) through the animal model to estimate the additive genetic variance and breeding value of individuals have been outlined by Lynch and Walsh (1998) and Piepho et al. (2008). For BLUP estimations of breeding value, one of the key advantages over traditional linear models (that derive the general combining ability of an individual) is the use of the relationship matrix, which adjusts the BLUP value based on performance of an individual's relatives. The BLUP breeding value estimate derived in this fashion effectively incorporates among- and within-family genetic variance, which allows among- and within-family selection for an individual simultaneously.

This study examined an alternative strategy for developing machine-harvested red raspberries. A machine was used to bulk harvest all seedlings within a full-sib family plot to get bulk (combined) yield and then the yield data were apportioned to individual seedlings within the full-sib plot by using key yield component data developed by Stephens et al. (2012). The strategy was used to eliminate the need for costly and timeconsuming hand-harvest operations and would allow measurements to be carried out on large seedling populations. A combined breeding strategy could be applied whereby the machine-harvest yield was used to select better families and yield components used to select the best individuals within the better families. This strategy allows for selection of parents with improved combining ability for machine-harvest and also for selection for machine-harvest yield early in the development of new cultivars.

In the red raspberry pairwise genetic study described by Stephens et al. (2012), two plants within each plot of six full-sib seedlings were hand-harvested, whereas the remaining four were machine-harvested to give a bulk machine-harvest, whereas yield components were measured on all plants. Using these data, we determined if yield components could be used to apportion our bulk machine-harvest yield to individuals within a family, thus allowing selection among and within families based on an estimate of machine-harvest yield. We further investigated the implications such an approach would have on genetic gain per generation for a fixed cost.

\section{Materials and Methods}

Plants and experimental Design. Details of the parental material and experimental design are described by Stephens et al. (2012). Briefly, controlled crosses were carried out in a double pairwise design involving 45 parents, which should have resulted in 90 full-sib families with each parent being used in four families (twice as a female and twice as a male). However, failure of some crosses and poor seed germination meant there were only 85 families and a few instances in which the reciprocal cross was used because of the timing of the availability of flowers and pollen. Parents were all floricanefruiting red raspberry types and consisted of 18 breeding selections and three cultivars from the Plant \& Food Research or Plant \& Food Research-Northwest Plant raspberry breeding programs and 24 named cultivars from U.S. and Canadian breeding programs. Recent papers (Piepho and Williams, 2006) indicated that an $\alpha$-design (Patterson and Williams, 1976) was appropriate for plant breeding trials where there is a large number of families and small number of replications. There were two complete blocks, each with 12 sub-blocks of seven plots (i.e., 84 plots per block, which was sufficient because two of the 85 families had enough plants for only one plot). Each plot consisted of six full-sib seedling plants. Planted in May 2008, the trial was located at Enfield Farms Inc., Lynden, WA (lat. $48.935^{\circ} \mathrm{N}$, long. $122.542^{\circ} \mathrm{W}$ ). The seedlings were planted in rows with spacing $3 \mathrm{~m}$ between rows and $1 \mathrm{~m}$ between seedlings and managed according to standard agronomic practice. Thus, there were a total of 1008 plants in the trial with 12 plants per family (except for the two families with sufficient plants for only one plot).

Plant measurements. All data were collected in the 2009, 2010, and 2011 seasons when the plants were (from field planting) one, two, and three years old. For the first and second plant in each plot in 2010 and $2011(\mathrm{n}=336)$, total fruit yield (grams per plant) was measured by hand-picking and weighing total ripe fruit weight every $5 \mathrm{~d}$ throughout the season. The remaining four plants per plot were machine-harvested with an over-the-row XL 2007 harvester (Littau, Stayton, OR) every $5 \mathrm{~d}$ and bulk fruit from all plants weighed. Machine-harvest was conducted immediately after the first two plants in each plot were hand-harvested, and machine beaters turned off as the machine passed hand-harvested plants. In 2010, plants were hand-harvested 11 times and plots machine-harvested eight times, whereas in 2011, plants were hand-harvested 10 times and plots machine-harvested eight times.

Before fruit ripening in 2009 and 2010, the lateral lengths (centimeters) of six randomly chosen laterals from the upper, middle, and lower cane regions (i.e., two from each region) on all plants were measured. In both years, 30 berries were picked at each of three times during the season (early, middle, and late) for each plant, taken to the laboratory and weighed, from which average individual berry weight (grams) per plant was determined.

Cost estimates. We estimated the costs of both approaches (i.e., hand-harvest vs. machine-harvest) for 1000 seedlings and then proportioned the number of seedlings that could be evaluated for the same cost in each case. For both approaches, the costs of raising seedlings, planting, and field maintenance 
were taken into account. For hand-harvesting, costing took into account labor and for machine-harvesting, labor, fuel, and machine maintenance as well as lateral length and berry weight measurement costs:

$$
C_{H H}=H_{l} \cdot r_{l}+\left(F_{s}+F_{m}\right)+S
$$

where $C_{H H}=$ cost of hand-harvesting plants, $H_{l}=$ hours of labor to hand-harvest plants during season, $r_{l}=$ hourly pay rate, $F_{s}=$ cost of setting up field area of red raspberries, $F_{m}=$ cost of maintaining field area of red raspberries, and $S=$ cost of raising seedlings to ready-to-plant stage.

$$
C_{M H}=\left(H_{a}+H_{b}+H_{l}\right) \cdot r_{l}+H_{m} \cdot\left(r_{f}+r_{m}\right)+\left(F_{s}+F_{m}\right)+S
$$

where $C_{M H}=$ cost of machine-harvesting per plant, $H_{a}=$ hours of labor to measure lateral length, $H_{b}=$ hours of labor to measure berry weight, $H_{l}=$ hours of labor to required to machine-harvest plants during season (includes driver and two graders), $r_{l}=$ hourly pay rate, $H_{m}=$ hours of use of machine-harvester to harvest plants, $r_{f}=$ machine fuel cost per hour, $r_{m}=$ machine maintenance cost per hour, $F_{s}=$ cost of setting up field area of red raspberries, $F_{m}=$ cost of maintaining field area of red raspberries, and $S=$ cost of raising seedlings to the ready-to-plant stage.

Machine-harvester capital cost and depreciation or capital land value were not taken into account.

EMPIRICAL BREEDING VALUES. Calculations of hand-harvest empirical breeding values (eBVs) for two hand-harvested plants per plot were described by Stephens et al. (2012). Briefly, we used mixed models and BLUP (Lynch and Walsh, 1998) to estimate variance components. There were no fixed effects in the models and random effects included genotypes (i.e., individual plants), block, and sub-block. Empirical breeding values were obtained for the seedlings from the univariate analysis. Because the pedigree information was included, it was also possible to estimate the eBV for each parent. For machineharvest eBVs, we combined the machine-harvest yield data (four plants per plot) with hand-harvest yield data (two plants per plot) to get a total yield estimate for each plot (six plants per plot). We averaged this total yield estimate over 2010 and 2011 and fitted a univariate mixed model (Lynch and Walsh, 1998) to derive variance components and eBV for each plot (Henderson, 1977). Genotypes, including the pedigree information, block, and sub-block, were fitted as random effects.
Stephens et al. (2012) identified berry weight and lateral length as the two most important yield components contributing to total yield and showed that a weighted average of the 2009 and 2010 data (weighted 1:3 2009:2010 respectively) best predicted total yield in 2010 and 2011. Using eBVs derived from bivariate analysis of these weighted averages, we calculated the product of berry weight and lateral length, $\mathrm{YC}_{\text {prod }}$, for each seedling. We apportioned the plot machine-harvest eBV to each individual seedling in the plot according to the value of the seedling's $\mathrm{YC}_{\text {prod, }}$ so that the within-family yield was expressed in the same terms as the among-family yield:

$$
\mathrm{eBV}_{\text {MHYld }, \mathrm{i}}=\frac{\mathrm{eBV}_{\text {MHYld }} \times \mathrm{YC}_{\text {prod }, \mathrm{i}}}{\sum \mathrm{YC}_{\text {prod,i }}}
$$

where $\mathrm{eBV}_{\text {MHYld,i }}$ is the eBV for the machine-harvest yield of the $i^{\text {th }}$ seedling in the plot, $e B V_{\text {MHYld }}$ is the machine-harvest eBV for the entire plot, $\mathrm{YC}_{\text {prod, } i}$ is the $\mathrm{YC}_{\text {prod }}$ for the $\mathrm{i}^{\text {th }}$ seedling in the plot, and the sum $\left(\sum \mathrm{YC}_{\text {prod,i }}\right)$ is overall seedlings in the plot. Finally, to obtain machine-harvested eBV, we fitted a bivariate model to this estimated seedling machine-harvest yield and $\mathrm{YC}_{\text {prod. }}$. We compared these values with the eBVs from the univariate analysis of the mean of 2010 and 2011 yield from individually hand-harvested seedlings (two per plot).

Genetic Gain. Genetic gain for yield over the two years (2010 and 2011) was estimated using simulation following the method advocated by Piepho and Mohring (2007). In their work, Piepho and Mohring (2007) suggest that genetic gain is more accurately estimated using a direct simulation approach rather than the more traditional approach that uses heritability estimates derived from variance components. We used fitted values from the final bivariate model as the actual values and achieved 1000 data sets to analyze by adding random samples (taken with replacement) of the residuals to these. For hand-harvesting, for each run it was first necessary to take a random subset of the seedlings because for a fixed cost, fewer seedlings could be evaluated. This was achieved by taking two randomly selected seedlings from each plot $(\mathrm{n}=$ 336), thereby retaining the experimental structure. For each simulated data set, the predicted top 10, 20,30,40, and 100 seedlings (i.e., those with the highest eBV) were identified. Genetic gain was computed as the difference between the mean of the selected population and overall population mean, where means were based on the actual values. Ten, 20, 30, 40,

\begin{tabular}{|c|c|c|c|c|c|c|}
\hline \multirow[b]{2}{*}{ Cost item } & \multicolumn{3}{|c|}{ Hand-harvest } & \multicolumn{3}{|c|}{ Machine-harvest } \\
\hline & Time (h) & Rate $(\$ / \mathrm{h})$ & Total $(\$)$ & Hours & Rate $(\$ / \mathrm{h})$ & Total $(\$)$ \\
\hline Lateral length measurements & & & & 48 & 12 & 576 \\
\hline Berry weight measurements & & & & 48 & 12 & 576 \\
\hline Machine fuel & & & & 48 & 7 & 336 \\
\hline \multirow[t]{2}{*}{ Machine maintenance } & & & & 48 & 5.5 & 264 \\
\hline & Area (ha) & Rate $(\$ / \mathrm{ha})$ & Total $(\$)$ & Area (ha) & Rate $(\$ /$ ha $)$ & Total (\$) \\
\hline \multirow[t]{2}{*}{ Field area maintenance } & 0.0 & 0 & 0 & 19.4 & 30 & 576 \\
\hline & Plants (no.) & Rate (\$/plant) & Total $(\$)$ & Plants (no.) & Rate (\$/plant) & Total (\$) \\
\hline Seed germination and nursery & 1,000 & 2 & 2,000 & 1,000 & 2 & 2,000 \\
\hline Total $(\$)$ & & & 19,400 & & & 5,480 \\
\hline
\end{tabular}

Table 1. Estimated commercial direct costs associated with growing and harvesting 1000 seedlings by machine-harvest and hand-harvest strategies for a red raspberry breeding program for one year. 
and 100 seedlings were chosen to correspond to a proportion selected of $1 \%, 2 \%, 3 \%, 4 \%$, and $10 \%$, respectively, based on the entire population of 1008 seedlings (which was used for the machine-harvest approach).

For hand-harvesting, genetic gain estimates were obtained using univariate analysis of the yields. The actual population mean differed for each data set because each set was a random subsample of the entire population. For machine-harvesting, the simulated data set was analyzed as described in the empirical breeding values section. The actual population mean was the same for all data sets because there was no subsampling.

All statistical analyses were conducting using R 2.12.0 ( $\mathrm{R}$ Core Development Team, 2010) and the mixed models were fitted using the asreml-r package (Butler et al., 2006).

\section{Results}

Cost estimates. We estimated the direct costs for growing 1000 red raspberry seedlings and hand-harvesting vs. machineharvesting for one year (Table 1). Based on our estimated costs we found we could machine-harvest nearly three times more seedlings than could be hand-harvested.

EMPIRICAL BREEDING VALUES. Using machine-harvest and yield component (berry weight and lateral length) data we calculated individual machine-harvest eBVs for all individuals and parents of the red raspberry pairwise genetic study (Table 2). Parental (Tables 2 and 3) and seedling (Fig. 1) eBVs for machine-harvest yield were, in all but one case, considerably lower than those estimated for handharvest yield. The magnitude of the discrepancy increased as the estimate eBV increased (Table 2). In general, those parents with high eBV for yield as determined by handharvesting had high machine-harvested yield eBV, although there were some exceptions. For example, 'Wakefield' was ranked midrange for hand-harvested eBV but was one of the highest for machine-harvest (Table 2). 'Meeker' had a higher hand-harvest eBV than 'Wakefield' but a lower machine-harvest eBV. It is also interesting to note that the top five parents for hand-harvested yield were closely related (Fig. 2).

Top-performing individuals came predominantly from certain families and 25 of the 30 top-performing individuals (based on machine-harvest eBVs) came from the 10 top families (Table 3). Higher numbers of transgressive segregants (i.e., those seedlings with eBV higher than either parent) were found in top-performing families than in bottom-performing families for machine-harvest.

Genetic Gain. Based on a fixed cost, a breeding program relying on hand-harvesting could only assess approximately one-third of the plants that could be assessed using the proposed machine-harvest strategy. Thus, the expected genetic gain in yield per generation from hand-harvesting based on one-third of the population size (i.e., same cost) was less than that from the machine-harvesting approach over all selection intensities (Table 4). The mean total yield eBV for the unselected population was $2441 \mathrm{~g} / \mathrm{plant}$ and thus the expected mean genetic gain per generation in total yield (average over $1 \%$, $2 \%, 3 \%, 4 \%$, and $10 \%$ selected) was $6.5 \%$ and $7.6 \%$ for handand machine-harvest, respectively. As the number selected increased, the difference between the two strategies increased (Table 4). For the machine-harvest strategy, the mean total
Table 2. Mean 2010 and 2011 hand-harvested total yield empirical breeding value (eBV) and mean 2010 and 2011 machine-harvested total yield eBV (from bivariate model with berry weight $\times$ lateral length $\mathrm{eBV}$ ) for parents of red raspberry pairwise study (sorted from highest to lowest machine-harvested yield).

\begin{tabular}{|c|c|c|c|}
\hline Parent & Source ${ }^{z}$ & $\begin{array}{l}\text { Hand-harvested } \\
\text { total yield (g) }\end{array}$ & $\begin{array}{l}\text { Machine-harvested } \\
\text { total yield (g) }\end{array}$ \\
\hline$\overline{Z N K 018}$ & BS & 3934 & 2699 \\
\hline ZNK019 & $\mathrm{BS}$ & 3974 & 2684 \\
\hline ZNJ042 & BS & 3509 & 2673 \\
\hline 'Tulameen' & SB & 3755 & 2672 \\
\hline HR122 & $\mathrm{BS}$ & 3857 & 2671 \\
\hline ZNK063 & BS & 3871 & 2664 \\
\hline 'Wakefield' & PFR & 3192 & 2661 \\
\hline NR3 & $\mathrm{BS}$ & 3492 & 2660 \\
\hline ZN05022 & BS & 3441 & 2642 \\
\hline NR4 & BS & 3723 & 2638 \\
\hline NR9 & BS & 3261 & 2635 \\
\hline NR10 & $\mathrm{BS}$ & 3553 & 2628 \\
\hline HR149 & $\mathrm{BS}$ & 3906 & 2582 \\
\hline 'Motueka' & PFR & 3485 & 2576 \\
\hline ‘Saanich’ & NWP & 3371 & 2549 \\
\hline ZN05005 & $\mathrm{BS}$ & 3618 & 2543 \\
\hline 'Cowichan' & NWP & 3044 & 2540 \\
\hline HR158 & $\mathrm{BS}$ & 3636 & 2534 \\
\hline 'Coho’' & NCGR & 3182 & 2518 \\
\hline HR104 & BS & 3212 & 2502 \\
\hline 'Meeker' & NWP & 3424 & 2493 \\
\hline 'Chilliwack' & NCGR & 2953 & 2481 \\
\hline 'Encore' & NF & 3157 & 2463 \\
\hline ZNM001 & $\mathrm{BS}$ & 3497 & 2447 \\
\hline ZN05012 & $\mathrm{BS}$ & 3497 & 2441 \\
\hline ZN05015 & BS & 2795 & 2430 \\
\hline 'Cuthbert' & NCGR & 3186 & 2426 \\
\hline ZNM003 & BS & 2903 & 2424 \\
\hline ZNK033 & BS & 3532 & 2406 \\
\hline 'Moutere' & PFR & 3174 & 2406 \\
\hline 'Haida' & NF & 3380 & 2391 \\
\hline 'Titan’ & $\mathrm{NF}$ & 2860 & 2390 \\
\hline ‘Lauren' & NF & 2865 & 2354 \\
\hline 'Nootka' & NCGR & 3000 & 2346 \\
\hline NR12 & BS & 3046 & 2340 \\
\hline 'Taylor' & NCGR & 2675 & 2315 \\
\hline 'Willamette' & NWP & 2937 & 2312 \\
\hline ZN05018 & $\mathrm{BS}$ & 2546 & 2291 \\
\hline 'Vene' & NCGR & 2384 & 2289 \\
\hline ‘Killarney’ & NF & 2488 & 2171 \\
\hline 'Boyne’' & NF & 2305 & 2143 \\
\hline 'Prelude' & NF & 2309 & 2138 \\
\hline 'Latham' & NF & 2137 & 2091 \\
\hline K81-6 & NF & 1944 & 2059 \\
\hline 'Nova' & NF & 2048 & 1969 \\
\hline
\end{tabular}

$\overline{{ }^{\mathrm{z}} \mathrm{BS}}=$ Northwest Plant Co.-Plant and Food Research (Lynden, WA) breeding selection; $\mathrm{SB}=$ Sakuma Brothers $($ Burlington, WA $) ; \mathrm{PFR}=$ Plant and Food Research (Motueka, New Zealand); NWP = Northwest Plant Co. (Lynden, WA); NF = Nourse Farms (Whately, MA); NCGR = National Clonal Germplasm Respository (Corvallis, OR).

yield values were not lower than the hand-harvest strategy values because, although $\mathrm{eBV}$ was used to rank and select the top individuals, it was the mean of their actual values that was compared (Table 4). 
Table 3. Mean top 10 and bottom 10 (gray) family empirical breeding values (eBVs) for machine-harvest $(\mathrm{n}=12)$ and hand-harvest $(\mathrm{n}=4)$ total yield and associated SE, number of transgressive segregants (TS), and the number of seedlings within a family $(\mathrm{n}=12)$ that were in the top 30 machine-harvested eBVs of all seedlings in the red raspberry pairwise study.

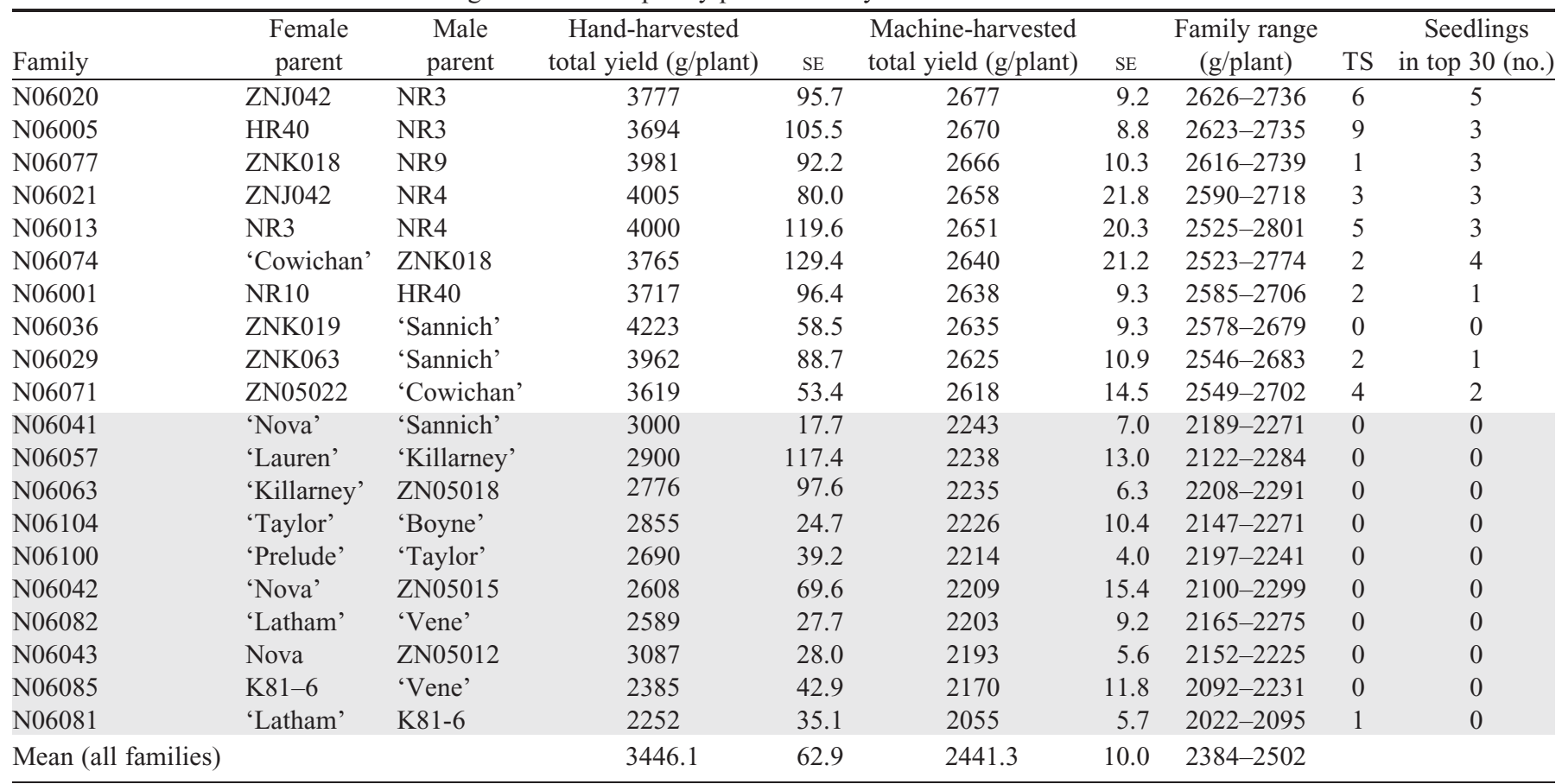

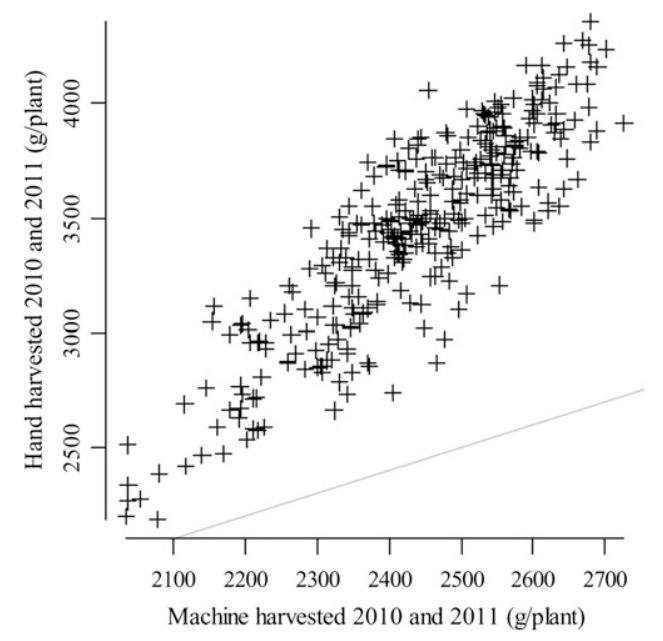

Fig. 1. Mean of 2010 and 2011 machine-harvested yield empirical breeding value (eBV) vs. mean 2010 and 2011 hand-harvested yield eBV for those hand-harvested individuals $(n=336)$ of the red raspberry pairwise study. The correlation coefficient is 0.86 and the gray line is that of equality.

\section{Discussion}

Obtaining individual machine-harvest yield eBVs for red raspberry breeding populations is not likely to be possible using a machine-harvester directly. However, we have shown that it is possible to estimate individual seedling machine-harvest eBVs by bulk harvesting full-sib families and using yield component data to derive indirect yield estimates for individual seedlings within families. We found that using this strategy, for the same cost, we could harvest three times as many seedlings and

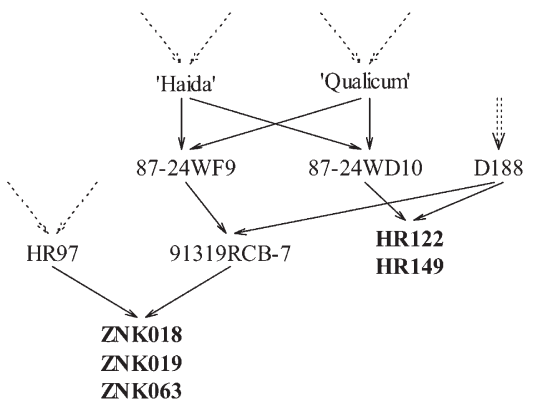

Fig. 2. Pedigree tree of top five parents (shown in bold) for hand-harvest empirical breeding values of the red raspberry pairwise study. Dotted lines indicate further known ancestors that are not shown (the double dotted line indicates a selfing). D188 is not known to be related to any of HR97, 'Haida', or 'Qualicum', but these three are distantly related to one another (coancestry coefficients are HR97: 'Haida' 0.11, HR97: 'Qualicum' 0.05, and 'Haida': 'Qualicum' 0.10).

achieve a higher genetic gain than we could by hand-harvesting seedlings.

Our estimated machine-harvest eBVs were well correlated but significantly lower than those estimated for hand-harvest. This is likely to be in part because on some individual plants, fruit are less easily removed, for example, because of strong attachment to the receptacle, and these are not as well harvested by machine, whereas during hand-harvesting these fruit are removed. Also, during machine-harvest, some fruit are lost on the ground, although this is not considered a large amount. Our harvest interval was $5 \mathrm{~d}$ and this is twice as long as that for commercial red raspberry machine-harvesting and loss of fruit associated with this could have also contributed to low 
Table 4. Mean total yield of selected individuals (and 95\% confidence interval), expected genetic gain per generation, at varying selection intensities, in total yield per generation for hand- $(n=336)$ and machine-harvest $(n=1008)$ selection strategies for mean of 2010 and 2011 of seedlings in the red raspberry pairwise study. ${ }^{2}$

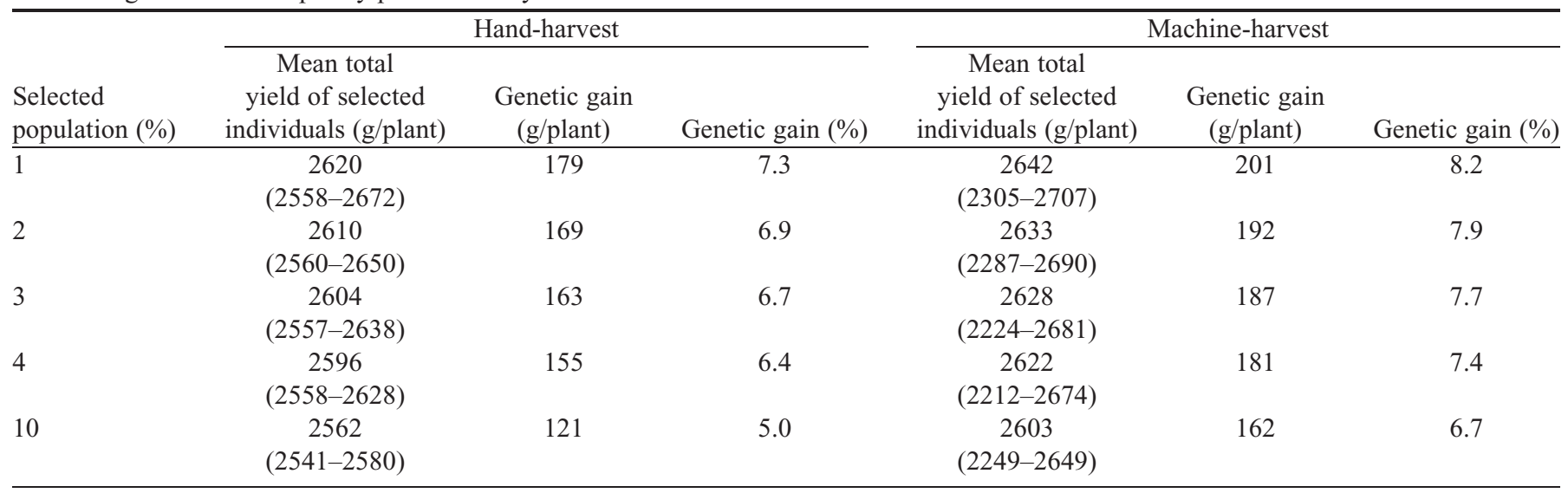

${ }^{\mathrm{z}}$ Mean of unselected population $=2441 \mathrm{~g}$.

machine-harvest eBVs. Another reason for the machine-harvest eBVs being lower than those from hand-harvest is because of the indirect nature used in obtaining individual seedling machine-harvest eBV, the heritability will be lower than for hand-harvesting and thus the "shrinkage" from the BLUP analysis will be greater. This would explain the greater discrepancy for parents with higher eBVs.

We found some differences in rankings for hand-harvest and machine-harvest yield eBVs and a likely reason for this is because genotypes vary in their ability to release fruit under machine-harvesting. For example, 'Wakefield' harvests extremely easily by machine and hence the estimated eBV for machine-harvest was relatively high compared with its handharvest eBV. In fact 'Wakefield' had the closest machineharvest $\mathrm{eBV}$ to hand-harvest $\mathrm{eBV}$ ratio of all of the top yielders. In contrast, 'Meeker', which does not harvest as well by machine, had a much higher eBV for hand-harvest than for machine-harvest. The use of the BLUP analysis allowed us to estimate the eBV of parents and ancestors of our study plants as well as for each individual seedling. This type of analysis enables breeders to select the best parental combinations for future crosses and, when combined with pedigree information, identifies key parental lines and ancestors for high yield.

Our analysis was based on using yield component data from the first and second fruiting years combined with the (mean) second and third fruiting years machine-harvest data. We also analyzed the data using machine-harvest data from 2010 only (first mature plant crop) and found similar genetic gain results between hand- and machine-harvest (percent average overall selection intensities, data not shown). Thus, it may be possible to make machine-harvest yield measurements in only one year.

In our analysis, to achieve machine-harvested total yield per plot, we added our machine-harvested four-plant plot yield to our hand-harvested yield for the remaining two plants per plot. This was necessary to enable us to compare machine with handharvest and to complete the analysis on plots. Further work needs to be done to determine optimum size of full-sib family plots to reduce the effort to gain machine-harvest yield data without compromising the prediction accuracy of yield eBVs.

One of the potential downsides of the BLUP approach with the relationship matrix is that it tends to lead to selections being made from fewer families than should the relationship matrix be ignored. However, strategies to prevent this have been discussed by others (e.g., Kumar et al., 2010) and introgression of new genetic material into the breeding program will assist with this.

In summary, in developing genotypes suited to machineharvest, we suggest that our approach delivers greater genetic gain than hand-harvesting for the same cost. It has the additional benefit of identifying individuals or families that do not release their fruit well and thus harvest poorly by machine (despite having high yield by hand-harvest). The use of bulk harvest for yield measurement allows among-family selection and this, coupled with derived yield estimates for individuals within the best families, is a breeding strategy used in several crops but which has had limited application to fruit crops. We suggest that this breeding approach could have an application in other machine-harvested crops, especially perennial small fruit crops such as blueberry and black currant.

\section{Literature Cited}

Bischoff, K.P. and K.A. Gravois. 2004. The development of new sugarcane varieties at the Louisiana State University AgCenter. J. Amer. Soc. Sugar Cane Technol. 24:142-164.

Butler, D.G., B.R. Cullis, A.R. Gilmour, and B.J. Gogel. 2006. ASReml-R reference manual, release 2. Queensland Department of Primary Industries and Fisheries, Brisbane, Australia.

Falconer, D.S. and T.F.C. Mackay. 1996. Introduction to quantitative genetics. Longmans Green, Harlow, UK.

Hall, H.K., M.J. Stephens, P. Alspach, and C.J. Stanley. 2002. Traits of importance for machine harvest of raspberries. Acta Hort. 585:607-610.

Hallauer, A.R., M.J. Carena, and J.B.M. Filho. 2010. Quantitative genetics in maize breeding. Springer, New York, NY.

Henderson, C.R. 1977. Best linear unbiased estimation and prediction under a selection model. Biometrics 31:423-477.

Kempler, C., H.A. Daubeny, L. Frey, and T. Walters. 2006. 'Chemainus' red raspberry. HortScience 41:1364-1366.

Kempler, C., H.A. Daubeny, B. Harding, T. Baumann, C.E. Finn, P.P. Moore, M. Sweeney, and T. Walters. 2007. 'Saanich' red raspberry. HortScience 42:176-178.

Kimbeng, C.A. and M.C. Cox. 2003. Early generation selection of sugarcane families and clones in Australia: A review. J. Amer. Soc. Sugar Cane Technol. 23:20-39.

Kumar, S., R.K. Volz, P.A. Alspach, and V.G.M. Bus. 2010. Development of a recurrent apple breeding programme in New Zealand: 
A synthesis of results, and a proposed revised breeding strategy. Euphytica 173:207-222.

Lynch, M. and B. Walsh. 1998. Estimation of breeding values, p. 745778. In: Lynch, M. and B. Walsh (eds.). Genetics and analysis of quantitative traits. Sinauer Assoc., Sunderland, MA.

Moore, P.P. and H.A. Daubeny. 1993. 'Meeker' red raspberry. Fruit Var. J. 47:2-4.

Moore, P.P. and C.E. Finn. 2007. 'Cascade Bounty' red raspberry. HortScience 42:393-396.

Patterson, H.D. and E.R. Williams. 1976. A new class of resolvable incomplete block designs. Biometrika 63:83-92.

Piepho, H.P. and J. Mohring. 2007. Computing heritability and selection response from unbalanced plant breeding trials. Genetics 177:1881-1888.

Piepho, H.P., J. Mohring, A.E. Melchinger, and A. Buchse. 2008. BLUP for phenotypic selection in plant breeding and variety testing. Euphytica 161:209-228.
Piepho, H.P. and E.R. Williams. 2006. A comparison of experimental designs for selection in breeding trials with nested treatment structure. Theor. Appl. Genet. 113:1505-1513.

R Core Development Team. 2010. R: A language and environment for statistical computing. 1 Feb. 2011. <http://www.R-project.org>.

Stephens, M.J., P. Alspach, R.A. Beatson, C. Winefield, and E. Buck. 2012. Genetic parameters and breeding for yield in red raspberry. J. Amer. Soc. Hort. Sci. 137:229-235.

Stephens, M.J., J. Scalzo, P.A. Alspach, R.A. Beatson, and A.M. Connor. 2009. Genetic variation and covariation of yield and phytochemical traits in a red raspberry factorial study. J. Amer. Soc. Hort. Sci. 134:445-452.

Stringer, J.K., M.C. Cox, F.C. Atkin, X. Wei, and D.M. Hogarth. 2011. Family selection improves the efficiency and effectiveness of selecting original seedlings and parents. Sugar Tech 13: 36-41. 